\title{
Clinical analysis of 33 cases with neonatal cerebral infarction
}

\author{
Ning Yang ${ }^{1}$, Xiaojun He${ }^{2}$, Cuixia Yin ${ }^{3}$, Lihua Zhao ${ }^{4}$
}

\begin{abstract}
Objective: To investigate the etiology, clinical manifestations, diagnosis, treatment and prognosis of neonatal cerebral infarction $(\mathrm{NCl})$ to further improve the understanding of the disease.

Methods: Clinical data and follow-up results of 33 cases of $\mathrm{NCl}$ in neonatal intensive care unit of a firstclass hospital from September 2009 to September 2019 were retrospectively analyzed.

Results: All 33 patients were diagnosed with $\mathrm{NCl}$ by MRI. Among them, 31 cases $(93.94 \%)$ were fullterm infants, 25 cases (75.76\%) were mother's first birth, and 18 (54.55\%) cases were males. Pregnancy complications were reported in 18 cases $(54.55 \%)$, and 19 cases $(57.58 \%)$ had perinatal hypoxia history. Seizures were the most common first symptom and clinical manifestation in the course of disease (81.8\%). There were 27 cases $(81.82 \%)$ of patent foramen ovale (PFO) among $\mathrm{NCl}$ cohort. Ischemic cerebral infarction occurred in 32 cases $(96.97 \%)$. The middle cerebral artery and its branches were more frequently involved, mainly on the left side. The acute stage of $\mathrm{NCl}$ was managed by symptomatic support treatment, and the recovery stage involved mainly rehabilitation treatment. Among the 33 cases, five cases were lost to follow-up, two patients died, 26 patients survived without complications, one case had cerebral palsy, one case had language retardation, and six cases had dyskinesia. Poor prognosis was associated with the involvement of deep gray matter nuclei or multiple lobes, and intrapartum complications. Vaginal mode of delivery and longer hospital stay were associated with better prognosis.

Conclusions: Complications leading to placental circulation disorder during pregnancy and perinatal hypoxia are common high-risk factors of $\mathrm{NCl}$. The seizure is the most common clinical manifestation. There is a possible correlation between PFO and $\mathrm{NCl}$. Involvement of deep gray matter or multiple lobes and intrapartum complications may indicate poor prognosis, while vaginal delivery and prolonged hospitalizations are associated with better prognosis of $\mathrm{NCl}$.
\end{abstract}

KEYWORDS: Cerebral Infarction, Clinical Analysis, Infant, Newborn.

doi: https://doi.org/10.12669/pjms.37.7.4720

How to cite this:

Yang N, He X, Yin C, Zhao L. Clinical analysis of 33 cases with neonatal cerebral infarction. Pak J Med Sci. 2021;37(7):1800-1807. doi: https://doi.org/10.12669/pjms.37.7.4720

This is an Open Access article distributed under the terms of the Creative Commons Attribution License (http://creativecommons.org/licenses/by/3.0), which permits unrestricted use, distribution, and reproduction in any medium, provided the original work is properly cited.

1. Ning Yang,

Neonatal Department, Dezhou People's Hospital,

Dezhou 253000, Shandong, China.

2. Xiaojun $\mathrm{He}$,

3. Cuixia Yin,

4. Lihua Zhao,

2-4: Neonate Department, Ningjin County People's Hospital, Dezhou 253400, Shandong, China.

Note: Ning Yang and Xiaojun He are co-first authors and they contributed equally to this study. Correspondence:

Dr. Ning Yang,

Neonatal Department, Dezhou People's Hospital,

1166 Dongfanghong West Rd, Dezhou 253000, Shandong, China.

E-mail: kexintanyong@sina.com

* Received for Publication:

April 26, 2021

* $1^{\text {st }}$ Revision Received:

* $2^{\text {nd }}$ Revision Received:

* Final Revision Accepted:
May 17, 2021

June 21, 2021

July 6, 2021

\section{INTRODUCTION}

Neonatal cerebral infarction (NCI), also known as neonatal cerebral stroke, refers to the occlusion of one or more branches of neonatal cerebral vessels within 28 days after birth due to various reasons, leading to focal or multifocal ischemic necrosis in the corresponding blood supply area. ${ }^{1}$ Cerebral infarction includes arterial ischemic stroke (AIS) and hemorrhagic infarction. AIS is the most common type of cerebral infarction and accounts for about $90 \%$ of all the NCI cases. ${ }^{2}$ It can occur in the anterior, middle and posterior cerebral arteries, with the left middle cerebral artery being 
the most common location. ${ }^{3}$ At present, the risk factors of NCI are still unclear, and the clinical manifestations are diverse, making early diagnosis difficult. Recent developments in neuroimaging technology in newborns has allowed to establish that $\mathrm{NCI}$ is not uncommon, with the incidence rate of about $1 / 1600-3000,{ }^{1}$ markedly higher than the incidence of cerebral infarction in children and similar to the rate in elderly adults. ${ }^{4,5}$ In some cases, NCI may leave some sequelae such as dyskinesia, cognitive impairment, cerebral palsy and epilepsy that have a significant negative impact on the quality of life as well as financial burden to the healthcare system. ${ }^{6-8}$ In the recent study, the clinical data and prognosis of 33 cases of NCI in a first class hospital were retrospectively analyzed to provide clinical research data for further understanding the characteristics of NCI.

\section{METHODS}

Medical records of children with NCI, 18 males $(54.55 \%)$ and 15 females $(45.45 \%)$, were retrospectively analyzed in the Department of Neonatology of a first-class hospital from September 2009 to September 2019. This study was approved by the medical ethics committee of Dezhou People's Hospital (Ref. 20210079, date of approval: 2021 April, $\left.9^{\text {th }}\right)$. Informed consent was obtained from the guardians of the children.

Clinical data were collected and recorded, including gestational age, gender, birth weight, maternal disease history, family history, perinatal hypoxia history, perinatal infection history, delivery situation, cardiac color Doppler ultrasound examination, blood routine examination, coagulation function, first symptom, hospitalization time, short-term and long-term prognosis, magnetic resonance imaging (MRI) examination results.

For newborns with clinical history of intrauterine distress or asphyxia during labor and clinical manifestations of convulsion, poor reaction, cyanosis, recurrent apnea and severe jaundice, the head MRI scan was performed, including transverse T1 weighted imaging (T1WI), T2 weighted imaging (T2WI), T2 fluid attenuated inversion recovery (T2-FLAIR), diffusion weighted imaging (DWI) and sagittal T1WI. In cases of NCI, parallel Magnetic resonance angiography (MRA) was performed based on the results of MRI.

Statistical Analysis: Statistical analysis was performed using R Software Version 3.5.3 (R Core Team, 2019). Categorical variables were presented as counts and \% of total and comparisons based on prognosis were made using chi-square tests. Distribution of continuous data was determined using the Kolmogorov-Smirnov test. Continuous variables were presented as mean and \pm standard deviation (SD) and median and interquartile range (IQR). Comparisons based on prognosis for nonparametric variables were made using MannWhitney U tests. For all tests, p-values $<0.05$ were considered statistically significant. Prognosis was determined by medical assessment made during follow-up visits starting at two weeks after discharge and continuing once a month until the patient reaches two years of age.

\section{RESULTS}

As summarized in Table-I, the mean gestational age, mean $( \pm S D)$, of 33 hospitalized NCI infants included in the study was $38.52( \pm 1.42)$ weeks. The average maternal age was $28.79( \pm 3.52)$ years and mean paternal age was $29.8( \pm 5.3)$ years. All the included cases were single births, and $25(75.76 \%)$ were first births. There were 17 cases of cesarean section $(51.52 \%)$ and 16 cases of vaginal delivery $(48.48 \%)$. Two infants were premature $(6.06 \%)$ and 31 were full-term $(93.94 \%)$. The average birth weight was $3.37( \pm 0.54) \mathrm{kg}$, including one low birth weight infant $(3.03 \%)$ and four macrosomia infants $(12.0 \%)$. Seven percent of infants had Apgar score of 10 at one minute, rising to $26 \%$ at five minutes after birth. The earliest NCI onset was postnatal, and the latest onset was 20 days after birth. The age of admission ranged between one hour and $20 \mathrm{~d}$ after birth. Among them, 26 patients $(78.79 \%)$ were admitted within three days after birth, with an average length of stay of 15.45 ( \pm 13.61$)$ days (Table-I).

In $54.5 \%$ of included cases there was a normal prognosis of $\mathrm{NCI}, 30.3 \%$ reported adverse outcomes, and $15.2 \%$ of the cases were not followed-up. There were 18 recorded cases $(54.55 \%)$ of gestational complications, which included gestational diabetes mellitus, hypothyroidism, subclinical hyperthyroidism, antenatal cold and fever, anemia during pregnancy, and vaginitis. Intrapartum complications, such as amniotic fluid meconium, premature rupture of membranes, oligohydramnios, nuchal cord, and resuscitation were reported in $42.4 \%$ of the cases.

Clinical manifestations and complications: Clinical manifestations and complications of NCI patients are summarized in Table-II. Among the 33 cases, $25(75.76 \%)$ were admitted to hospital with seizures 
Table-I: Demographic and delivery variables $(\mathrm{N}=33)$.

\begin{tabular}{|c|c|c|c|}
\hline & & Cases (\%) & Mean $( \pm S D)$ \\
\hline \multirow[t]{2}{*}{ Gender } & Male & $18(54.5)$ & \\
\hline & Female & $15(45.5)$ & \\
\hline \multirow{2}{*}{$\begin{array}{l}\text { Gestational } \\
\text { age (weeks) }\end{array}$} & Premature $(<37)$ & $2(6.1)$ & $38.5(1.4)$ \\
\hline & Full term ( $\geq 37)$ & 31 (93.9) & \\
\hline \multirow{3}{*}{$\begin{array}{l}\text { Birth } \\
\text { weight (g) }\end{array}$} & Low $(<2500)$ & $1(3.0)$ & 3371.1 \\
\hline & Normal & $28(84.8)$ & $(535.4)$ \\
\hline & High $(>4000)$ & $4(12.0)$ & \\
\hline \multirow[t]{2}{*}{$\begin{array}{l}\text { Mother's } \\
\text { age (years) }\end{array}$} & $\geq 35$ years & $2(6.1)$ & $28.8(3.5)$ \\
\hline & $<35$ years & 31 (93.9) & \\
\hline \multirow{2}{*}{$\begin{array}{l}\text { Father's } \\
\text { age (years) }\end{array}$} & $\geq 35$ years & $7(21.2)$ & $29.8(5.3)$ \\
\hline & $<35$ years & $26(78.8)$ & \\
\hline \multirow[t]{2}{*}{$\begin{array}{l}\text { Delivery } \\
\text { method }\end{array}$} & Vaginal & $16(48.5)$ & \\
\hline & Caesarean & $17(51.5)$ & \\
\hline \multirow[t]{2}{*}{ Gravidity } & Primigravida & $18(54.5)$ & \\
\hline & Multigravida & $15(45.5)$ & \\
\hline \multirow[t]{2}{*}{ Parity } & Primipara & $25(75.8)$ & \\
\hline & Multipara & $8(24.2)$ & \\
\hline \multirow[t]{2}{*}{$\begin{array}{l}\text { Apgar score } \\
\text { at } 1 \mathrm{~min}\end{array}$} & 10 & $7(21.2)$ & \\
\hline & 9 or less & $26(78.8)$ & \\
\hline \multirow{2}{*}{$\begin{array}{l}\text { Apgar score } \\
\text { at } 5 \mathrm{~min}\end{array}$} & 10 & $27(81.8)$ & \\
\hline & 9 or less & $6(18.8)$ & \\
\hline \multirow{2}{*}{$\begin{array}{l}\text { Prenatal com- } \\
\text { plications }\end{array}$} & Present & $18(54.5)$ & \\
\hline & None & $15(45.5)$ & \\
\hline \multirow{2}{*}{$\begin{array}{l}\text { Intrapar- } \\
\text { tum complica- } \\
\text { tions }\end{array}$} & Present & $14(42.4)$ & \\
\hline & None & $19(57.6)$ & \\
\hline \multirow[t]{4}{*}{ Prognosis } & Normal & $18(54.5)$ & \\
\hline & Adverse outcomes & $10(30.3)$ & \\
\hline & Loss to follow-up & $5(15.2)$ & \\
\hline & Mean $( \pm S D)$ & \multicolumn{2}{|c|}{ Median (IQR) } \\
\hline $\begin{array}{l}\text { Age at onset } \\
\text { (hours) }\end{array}$ & $50.6(89.4)$ & \multicolumn{2}{|l|}{$21(4-48)$} \\
\hline $\begin{array}{l}\text { Length of stay } \\
\text { (days) }\end{array}$ & $12.2(13.9)$ & \multicolumn{2}{|l|}{$9(7-14)$} \\
\hline \multicolumn{4}{|c|}{$\begin{array}{l}\text { All categorical variables displayed as cases and } \% \text { of total. } \\
\text { All continuous variables displayed as mean } \pm S D \text {, as cases }(\%) \\
\text { among categories of relevance to birth outcomes, or as mean } \\
\pm S D \text { and median (IQR). Prematurity was defined as }<37 \text { weeks } \\
\text { gestational age, low birth weight was defined as }<2500 \mathrm{~g} \text { birth } \\
\text { weight, and advanced parental age was defined as } \geq 35 \text { years. } \\
\text { Prenatal complications include diabetes, anemia, subclinical } \\
\text { hyperthyroidism, prenatal fever, hypothyroidism, and vaginitis. } \\
\text { Intrapartum complications include amniotic fluid meconium, } \\
\text { PROM, oligohydramnios, nuchal cord, and resuscitation. }\end{array}$} \\
\hline
\end{tabular}

Table-II: Clinical characteristics ( $\mathrm{N}=33)$.

\begin{tabular}{llc}
\hline & & Cases (\%) \\
\hline $\begin{array}{l}\text { Clinical mani- } \\
\text { festation of }\end{array}$ & Seizure & $25(75.8)$ \\
NCI & Weak reaction & $5(15.2)$ \\
& Jaundice & $2(6.1)$ \\
& Pale & $1(3.0)$ \\
EEG results & Abnormal & $24(72.7)$ \\
& Normal & $3(9.1)$ \\
Patent fora- & Present & $6(18.2)$ \\
men ovale & Absent & $27(81.8)$ \\
& Test not performed & $2(6.1)$ \\
\hline $\begin{array}{l}\text { All categorical variables displayed as cases and \% } \\
\text { of total. }\end{array}$ &
\end{tabular}

before admission as the major complaint, five cases were admitted with a weak reaction, two cases with jaundice and one case with pale skin. The average onset time of seizures was 44.8 hours after birth. Two patients were admitted to hospital for skin jaundice without any neurological manifestations. EEG results were abnormal in $72.7 \%$ of the examined. Comorbidities of the $33 \mathrm{NCI}$ patients were as follows: five had purulent meningitis, three had neonatal sepsis, two had atrial septal defect, 27 had patent foramen ovale, three had patent ductus arteriosus and one had decreased left ventricular systolic function. Out of 33 cases, $30 \mathrm{NCI}$ patients improved and were discharged, and three patients were discharged automatically after considering the prognosis. Five cases were lost the follow-up due to interruption or refusal of contact information (Table-II). After admission, 33 cases were given etiologic and symptomatic support treatment. Patients with seizures were given phenobarbital sodium to control the convulsions.

There were 27 cases $(81.82 \%)$ with convulsions before or after admission (Table-III). There were 13

Table-III: Characteristics of the reported seizures ( $N=27)$.

\begin{tabular}{llc}
\hline & & Cases (\%) \\
\hline Clinical mani- & Unilateral limb twitch & $13(48.14)$ \\
festation of & Right limb twitch & $10(37.1)$ \\
seizures & Left limb twitch & $3(11.1)$ \\
& Paroxysmal cyanosis & $4(14.8)$ \\
& Binocular gaze & $1(3.7)$ \\
\hline
\end{tabular}

All categorical variables displayed as cases and \% of total. 


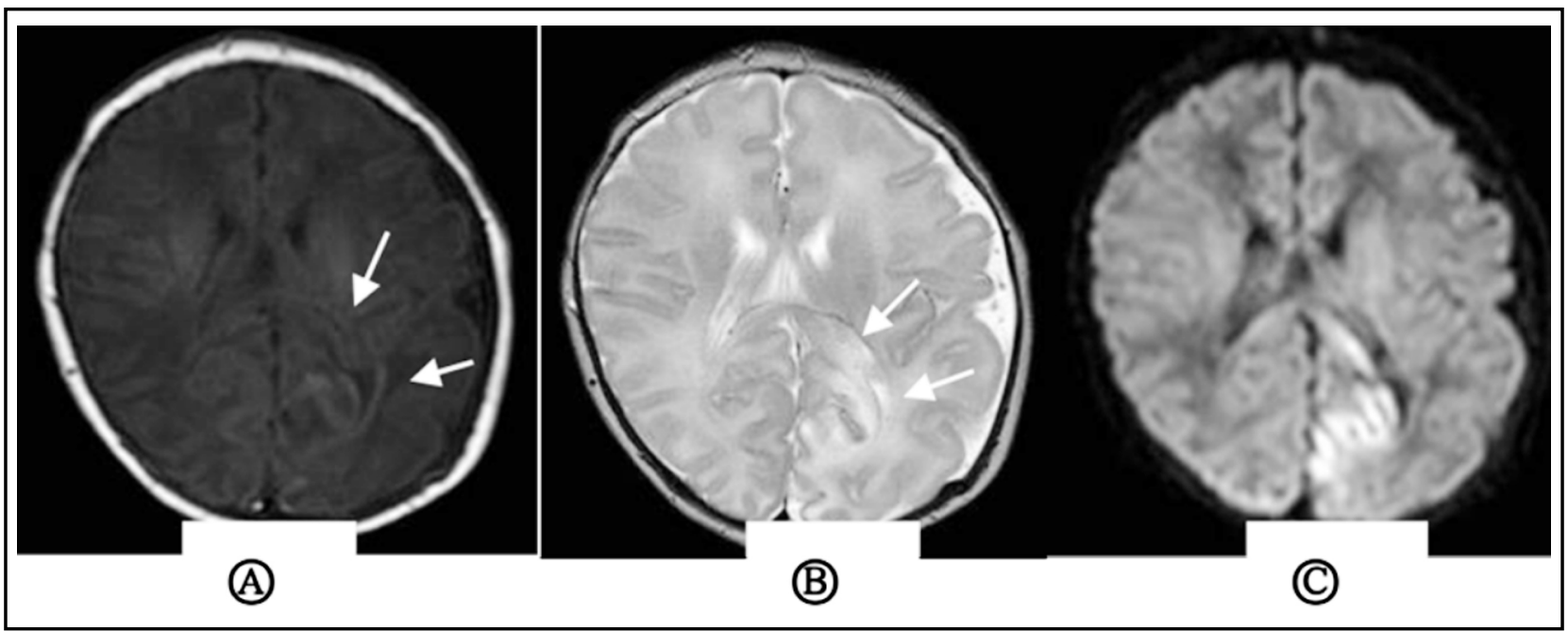

Fig.1: Magnetic resonance imaging findings in the left occipital of neonates with cerebral infarction A) as indicated by the arrows, T1WI suggests a large area of long T1 signal in the left occipital; B) as indicated by the arrow, T2WI suggests a large area of long T2 signal in the lesion area; C) diffusion weighted imaging (DWI) indicates a significant signal in the lesion.

cases with unilateral limb twitch, 10 cases on the right side, and three cases on the left side. There were four cases with paroxysmal cyanosis, apnea, limb shaking, and one case was binocular gaze.

Auxiliary examination: All 33 cases were examined by plain MRI that showed patchy T1 and T2 signals in the infarction area, and high signals in the infarction area on DWI (Fig.1). The lesions were located in the right side in 11 cases, the posterior cerebral artery in 3 cases, the anterior cerebral artery in one case, and the middle cerebral artery in seven cases; the lesions were located in the left side in 21 cases, the posterior cerebral artery in one case, and the middle cerebral artery in 20 cases; one case had a hemorrhage. Twenty-nine patients underwent MRA examination. The lumen of the feeding artery was narrowed in 18 cases, and the compensatory thickening of feeding artery was found in six cases $(82.76 \%)$. No abnormality was found in five cases.

Twenty-six patients received ambulatory electroencephalogram (AEEG) examination during their hospitalization. Three cases had normal AEEG results, and 23 were abnormal, presenting as sharp wave, spike wave, slow wave, spike slow wave, sharp slow wave and low voltage during sleep, etc.

We next evaluated the possible effect of

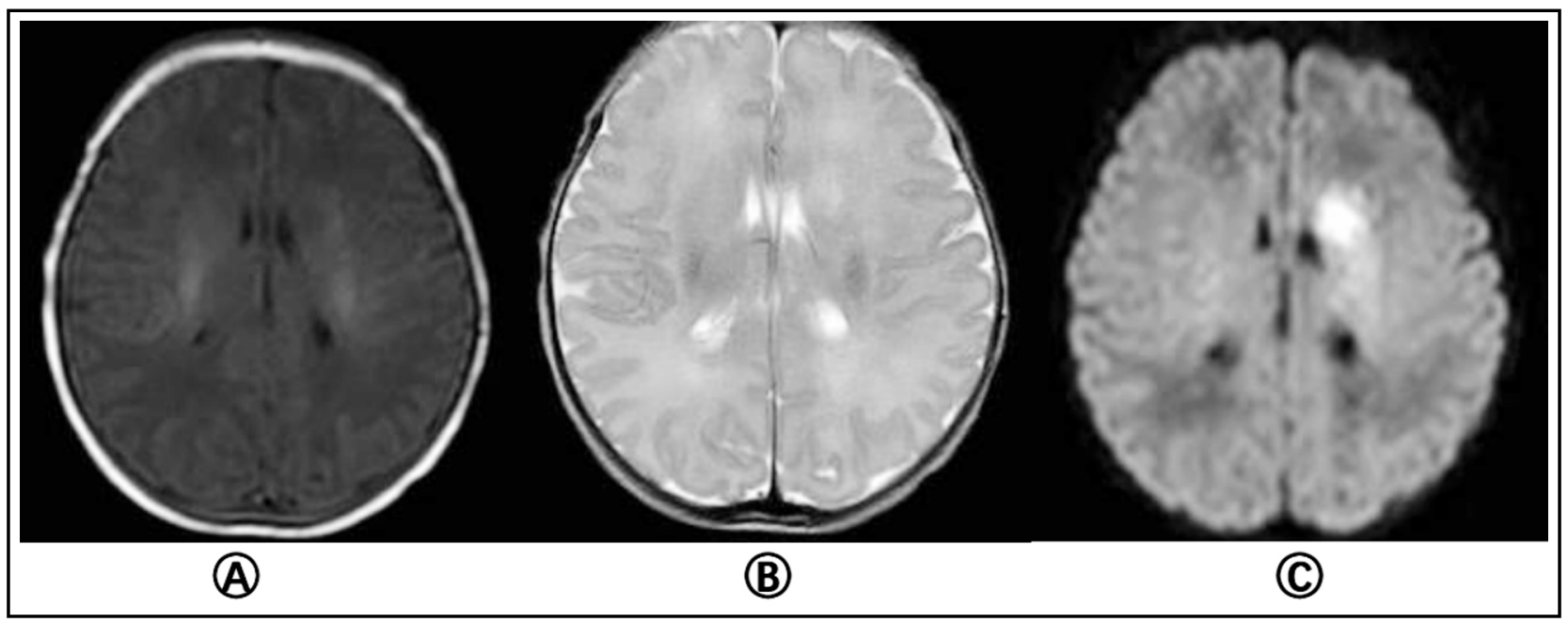

Fig.2: MRI findings of left basal ganglia in neonatal cerebral infarction a) T1WI showed long T1 signal in the left basal ganglia; B) T2WI showed long T2 signal in the lesion area; C) Diffusion weighted imaging (DWI) showed patchy hyperintensity in the left basal ganglia. 
Table-IV: Comparison of prognosis among demographic and delivery variables.

\begin{tabular}{|c|c|c|c|c|}
\hline & & Normal Cases (\%) & Adverse Outcomes Cases (\%) & p-value \\
\hline \multirow[t]{2}{*}{ Gender } & Male & $10(58.8)$ & $7(41.2)$ & 0.453 \\
\hline & Female & $8(72.7)$ & $3(9.1)$ & \\
\hline \multirow[t]{2}{*}{ Delivery method } & Vaginal & $11(84.6)$ & $2(15.4)$ & ${ }^{*} 0.037$ \\
\hline & Caesarean & $7(46.7)$ & $8(53.3)$ & \\
\hline \multirow[t]{2}{*}{ Gravidity } & Primigravida & $11(73.3)$ & $4(26.7)$ & 0.283 \\
\hline & Multigravida & $7(53.8)$ & $6(46.2)$ & \\
\hline \multirow[t]{2}{*}{ Parity } & Primipara & $14(70.0)$ & $6(30.0)$ & 0.318 \\
\hline & Multipara & $4(50.0)$ & $4(50.0)$ & \\
\hline \multirow[t]{2}{*}{ Apgar score at $5 \mathrm{~min}$} & 10 & $16(69.6)$ & $7(30.4)$ & 0.211 \\
\hline & 9 or less & $2(40.0)$ & $3(60.0)$ & \\
\hline
\end{tabular}

All variables were compared between cases with a normal prognosis $(\mathrm{N}=18)$ and cases with adverse outcomes ( $\mathrm{N}$ $=10$ ) and excluded loss to follow-up cases $(\mathrm{N}=5)$. Adverse outcomes included motor dysfunction, speech or motor delay, limb weakness or inflexibility, appendage adduction, and death. Comparisons were made using a chi-square test, with $\mathrm{p}<0.05^{*}$ considered statistically significant.

demographic parameters and delivery method on the prognosis of NCI patients. As shown in Table-IV, gender, gravidity, parity and lower Apgar score at five minutes did not impact the prognosis $(\mathrm{P}>0.05)$. On the other hand, vaginal birth was associated with a better prognosis, as compared to caesarian section $(\mathrm{P}=0.037)$.

Prenatal complications, clinical manifestations of $\mathrm{NCI}$, presence of foramen ovale and the age of NCI onset did not affect the outcome $(\mathrm{P}>0.05)$. However, intrapartum complications were associated with worse prognosis $(\mathrm{P}=0.046)$, and longer hospital stay correlated with better prognosis of NCI patients ( $\mathrm{P}>0.041)$.

\section{DISCUSSION}

The development of imaging technology in recent years significantly improved the diagnosis

Table-V: Comparison of prognosis among clinical characteristics.

\begin{tabular}{llccc}
\hline & & Normal Cases (\%) & Adverse Outcomes Cases (\%) & p-value \\
\hline Prenatal complications & Present & $9(52.9)$ & $8(47.1)$ & 0.119 \\
& None & $9(81.8)$ & $2(18.2)$ & \\
Intrapartum complications & Present & $4(40.0)$ & $6(60.0)$ & $* 0.046$ \\
& None & $14(77.8)$ & $4(22.2)$ & \\
Clinical manifestation of NCI & Seizure & $14(63.6)$ & $8(36.4)$ & 0.891 \\
& Other & $4(66.7)$ & $2(33.3)$ & 0.365 \\
Patent foramenovale & Present & $16(72.7)$ & $6(27.3)$ & \\
& Absent & $2(50.0)$ & $2(50.0)$ & p-value \\
& & Median (IQR) & Median (IQR) & 0.441 \\
Age at onset (hours) $\dagger$ & & $22.5(13-48)$ & $16(4.5-48)$ & $* 0.041$ \\
Length of stay (days) $\dagger$ & & $9.5(8-15)$ & $7(4-9)$ & \\
\hline
\end{tabular}

All variables were compared between cases with a normal prognosis $(\mathrm{N}=18)$ and cases with adverse outcomes ( $\mathrm{N}$ $=10)$ and excluded loss to follow-up cases $(\mathrm{N}=5)$. Adverse outcomes included motor dysfunction, speech or motor delay, limb weakness or inflexibility, appendage adduction, and death. Comparisons were made using a chi-square test for categorical variables or a Mann-Whitney U-test for non-parametric continuous variablest, with $\mathrm{p}<0.05^{*}$ considered statistically significant. 
rate of neonatal cerebral infarction. Nevertheless, the etiology and pathogenesis of $\mathrm{NCI}$ are still not completely clear, and there is a great need for effective early clinical interventions. NCI can be divided into ischemic cerebral infarction and hemorrhagic cerebral infarction, with arterial ischemic infarction (AIS) accounting for the majority of the lesions. ${ }^{9}$ In this study, $96.9 \%$ of the cases (32 out of 33) were diagnosed as AIS, a higher rate than that reported in the literature, probably due to the overall small number of cases. Previous studies have shown that the incidence of $\mathrm{NCI}$ in male is high, and the ratio of male to female is 1.3-1.6:1.10-12 Our results are in agreement with these reports, with males accounting for $54.55 \%$ of all patients.

The etiology of NCI is complex, with multiple contributing factors. Studies have shown that conditions, such as chorioamnionitis during pregnancy, preeclampsia, diabetes, autoimmune system related diseases, thrombotic diseases, infertility, primipara, smoking, fever, fetal heart rate decline during delivery, amniotic fluid and meconium contamination, emergency cesarean section, one minute Apgar score $<3$ points, and five minutes Apgar score $<7$ points all contribute to higher risk of developing NCI. ${ }^{13-16}$ In this study, there were 18 cases of pregnancy complications reported, including gestational diabetes mellitus, thyroid dysfunction, and infections. These conditions may potentially result in abnormal endothelial cell coagulation activity, uterine blood perfusion reduction, placental circulation disorder and dysfunction, as well as cerebrovascular regulation disorders, cerebral vasospasm, eventually leading to fetal and neonatal cerebral vasospasm infarction. Some studies have confirmed that NCI is more common in primiparas, probably because primipara increases the incidence of delivery complications, which can lead to asymptomatic hypoxia and ischemia in fetus or newborn. Although these conditions are not enough to cause hypoxic-ischemic encephalopathy, they may cause NCI in newborns with AIS..$^{10}$ Our data show that 25 cases $(75.76 \%)$ were firstborn, much higher than the percentage of non-primiparas $(24.24 \%)$, further confirming these reports.

Previous studies suggest that factors, such as vacuum delivery and emergency Caesarian section, are associated with an increased risk of NCI. ${ }^{17,18}$ In agreement with these reports, we show that vaginal delivery in our study is associated with an overall better prognosis of NCI as compared to caesarian section. Our study also showed that intrapartum complications in children with NCI were associated with a poor prognosis. Interestingly, patients with normal prognosis had significantly longer median length of hospitalization (9.5 days as compared to 7). This finding could indicate that longer hospital stays, and more healthcare resources and rehabilitation delivered to the patient are contributing to the better overall prognosis of NCI.

Severe infections and complications, such as sepsis and meningitis, are also important causes of cerebral infarction. NCI, secondary to bacterial meningitis, is often more severe and has worse prognosis. ${ }^{19}$ In this study, 5 cases of children with purulent meningitis were reported, but the prognosis was favorable. The relationship between these high-risk factors and AIS remains to be further confirmed.

In recent years, the link between patent foramen ovale (PFO) and cerebral infarction has become a research hotspot. In adults, $\mathrm{PFO}$ is considered an important risk factor for ischemic stroke. ${ }^{20}$ When the right atrial pressure increases, thrombosis in the venous system or cardiac cavity can enter the left ventricular system through the patent foramen ovale, resulting in cerebral embolism. ${ }^{21}$ However, foramen ovale is a normal blood circulation channel during the fetal period. After birth, the normal pulmonary circulation is established and left atrial pressure is increased, leading to gradual closure of foramen ovale. The unclosed foramen ovale in newborns is, therefore, temporal and physiological, and most of them are gradually closed within one year after birth. Studies have shown that $62 \%$ of full-term, healthy newborns have PFO in the first 60 hours after birth. ${ }^{22}$ In this group, 27 cases $(81.82 \%)$ had PFO, all of which were small and medium-sized. The average diameter of foramen ovale was $(2.63 \pm 0.51) \mathrm{mm}$. We may hypothesize that the cause of NCI in these cases is due to the increase of pulmonary artery pressure, which leads to the increase of right atrial pressure. After the embolus of the venous system returns to the right heart through the vena cava, it enters the left heart directly through the patent foramen ovale, and then flows into the systemic circulation, reaching and blocking the intracranial artery, which leads to cerebral ischemia. More studies are merited to establish the exact correlation between $\mathrm{NCI}$ and PFO.

Seizure is the most common clinical manifestation of NCI that occurs in $70 \%$ to $90 \%$ of children with $\mathrm{NCI} .{ }^{22}$ Seizures usually occur $12-72$ hours of birth ${ }^{2}$ 
and are usually manifested as local convulsions on the opposite side of the lesion. Our study shows that seizure is still the most common first symptom and the most common clinical manifestation of NCI. $75.76 \%$ of the children in our report were admitted to the hospital with convulsion as the main complaint, and $81.82 \%$ of the children had convulsions during the course of the disease. The average time of seizure was about 48 hours after birth, and about half of the children presented with contralateral limb twitching, which was consistent with the literature reports. ${ }^{2}$ Most of the children's clinical symptoms appear within three days after birth. Therefore, we should be alert to cerebral infarction, especially in children with unilateral limb twitch. In addition, other non-specific manifestations, such as paroxysmal cyanosis, apnea, poor reaction, severe jaundice, anemia of unknown causes, should all be evaluated to exclude intracranial lesions.

Cranial magnetic resonance imaging (MRI), including conventional MRI, diffusion weighted imaging (DWI) and magnetic resonance angiography (MRA), is the golden standard for NCI diagnosis. ${ }^{23}$ Conventional MRI of NCI brain usually shows T1WI low signal and T2WI high signal change within one week after the onset of $\mathrm{NCI}$, and high signal on T1WI and low signal on T2WI in lesion area one week later. DWI shows high signal in lesion area several hours after $\mathrm{NCI}$ onset, and the lesion location displayed in that early stage has a certain correlation with the clinical prognosis. ${ }^{23}$ Studies have reported that when DWI indicates early-stage damage to the internal capsule, basal ganglia, cerebral peduncle and other parts, it correlates with the increased incidence of long-term dyskinesia in children. ${ }^{24}$ MRA is a noninvasive vascular imaging reconstruction technique, that does not require contrast agent, and is utilized to diagnose cerebrovascular diseases, cerebrovascular stenosis, occlusion or malformation. ${ }^{25}$ In this study, 28 cases of acute or subacute cerebral infarction showed as isointense or slightly hypointense on T1WI, isointense or slightly hyperintense on T2WI and T2-FLAIR, hyperintense on DWI, and exhibited decreased apparent diffusion coefficient (ADC). Five cases of chronic cerebral infarction showed hyperintensity on T1WI, low signal on T2WI and T2-FLAIR, isointense or hypointense on DWI. Our study showed that the middle cerebral artery was most frequently involved in NCI, and the left side was higher than the right side.
While MRI combined with MRA is helpful for early detection of vascular abnormalities, studies have shown that early EEG has certain guiding significance for the evaluation of brain function and prognosis. EEG has been extensively used in children with seizures, suspected convulsions, and subclinical convulsions without typical clinical manifestations. ${ }^{26}$ In this study, 26 cases were examined by AEEG. Of them, abnormalities were detected in 23 cases, mainly manifested as abnormal high amplitude discharge and slow electrical activity. However, abnormal EEG had little correlation with poor prognosis. Further larger long-term follow-up studies are needed to evaluate the prognostic value of abnormal EEG in children with NCI.

The treatment of NCI is mainly symptomatic and supportive in the acute stage to maintain the stability of internal environment. Phenobarbital is used to stop spasms in patients with seizures, and rehabilitation treatment is mainly used in the recovery period. The reports on prognosis of neonatal cerebral infarction are quite different, ${ }^{4-6}$ and depend on the evaluation method, type and scope of infarction, and follow-up time. However, neonatal cerebral infarction is still one of the main causes of motor disorders, cerebral palsy, epilepsy, audiovisual and cognitive impairment. ${ }^{27}$ The incidence of sequelae in our study was $35.7 \%(10 / 28)$. The extent of cerebral infarction in children with poor prognosis mostly involved deep gray matter nuclei and multiple lobes, which was consistent with the literature reports. ${ }^{6}$

Limitation of the study: It includes small sample size. Although certain factors, including low birth weight, prematurity and low one minute Apgar score seem to indicate possible associations with poorer prognosis, the significance of these factors couldn't be calculated because of low case counts. Further larger-scale retrospective studies are needed to evaluate clinical impact of these factors on the prognosis of NCI.

\section{CONCLUSION}

Neonatal cerebral infarction is one of the brain injuries that seriously threaten the prognosis of the neonatal nervous system. Perinatal hypoxia is the main cause of cerebral infarction. Convulsion is the most common early clinical manifestation. Early detection and diagnosis combined with cranial imaging examination are 
of positive significance for judging prognosis, guiding rehabilitation treatment and improving prognosis.

\section{REFERENCES}

1. Dunbar M, Kirton A. Perinatal stroke: mechanisms, management, and outcomes of early cerebrovascular brain injury. Lancet Child Adolesc Health. 2018;2(9):666-676. doi: 10.1016/S2352-4642(18)30173-1

2. Bernson-Leung ME, Rivkin MJ. Stroke in Neonates and Children. Pediatr Rev. 2016;37(11):463-477. doi:10.1542/ pir.2016-0002

3. Machado V, Pimentel S, Pinto F, Nona J. Reply to letter to the editor on: perinatal ischemic stroke: a five-year retrospective study in a level-III maternity. Einstein (São Paulo). 2015;13(1):65-71. Einstein Sao Paulo Braz. 2015;13(3):478. doi:10.1590/S1679-45082015CE3439

4. Lehman LL, Khoury JC, Taylor JM, Yeramaneni S, Sucharew H, Alwell K, et al. Pediatric Stroke Rates Over 17 Years: Report From a Population-Based Study. J Child Neurol. 2018;33(7):463-467. doi: 10.1177/0883073818767039

5. deVeber GA, Kirton A, Booth FA, Yager JY, Wirrell EC, Wood E, et al. Epidemiology and Outcomes of Arterial Ischemic Stroke in Children: The Canadian Pediatric Ischemic Stroke Registry. Pediatr Neurol. 2017;69:58-70. doi: 10.1016/j.pediatrneurol.2017.01.016

6. Caspar-Teuscher M, Studer M, Regényi M, Steinlin M, Grunt S, Swiss Neuropediatric Stroke Registry Group. Health related quality of life and manual ability 5 years after neonatal ischemic stroke. Eur J Paediatr Neurol. 2019;23(5):716-722. doi: 10.1016/j.ejpn.2019.08.002

7. Grunt S, Mazenauer L, Buerki SE, Boltshauser E, Mori AC, Datta AN, et al. Incidence and outcomes of symptomatic neonatal arterial ischemic stroke. Pediatrics. 2015;135(5):e1220-e1228. doi: 10.1542/peds.2014-1520

8. Loo S, Ilves P, Mannamaa M, Laugesaar R, Loorits D, Tomberg T, et al. Long-term neurodevelopmental outcome after perinatal arterial ischemic stroke and periventricular venous infarction. Eur J Paediatr Neurol. 2018;22(6):10061015. doi: 10.1016/j.ejpn.2018.07.005

9. Ferriero DM, Fullerton HJ, Bernard TJ, Billinghurst L, Daniels SR, DeBaun MR. et al. Management of Stroke in Neonates and Children: A Scientific Statement From the American Heart Association/American Stroke Association. Stroke. 2019;50(3):e51-e96. doi: 10.1161/ STR.0000000000000183

10. Martinez-Biarge M, Cheong JLY, Diez-Sebastian J, Mercuri E, Dubowitz LMS, Cowan FM. Risk Factors for Neonatal Arterial Ischemic Stroke: The Importance of the Intrapartum Period. J Pediatr. 2016;173:62-68.e1. doi: 10.1016/j.jpeds.2016.02.064

11. Cole L, Dewey D, Letourneau N, Kaplan BJ, Chaput K, Gallagher C, et al. Clinical Characteristics, Risk Factors, and Outcomes Associated With Neonatal Hemorrhagic Stroke: A Population-Based Case-Control Study. JAMA Pediatr. 2017;171(3):230-238. doi: 10.1001/jamapediatrics.2016.4151

12. Villapol S, Faivre V, Joshi P, Moretti R, Besson VC, Charriaut-Marlangue C. Early Sex Differences in the Immune-Inflammatory Responses to Neonatal Ischemic Stroke. Int J Mol Sci. 2019;20(15):3809. doi: 10.3390/ ijms20153809

13. Rattani A, Lim J, Mistry AM, Prablek MA, Roth SG, Jordan LC, et al. Incidence of Epilepsy and Associated Risk Factors in Perinatal Ischemic Stroke Survivors. Pediatr Neurol. 2019;90:44-55. doi: 10.1016/j.pediatrneurol.2018.08.025
14. Li C, Miao JK, Xu Y, Hua YY, Ma Q, Zhou LL et al. Prenatal, perinatal and neonatal risk factors for perinatal arterial ischaemic stroke: a systematic review and meta-analysis. Eur J Neurol. 2017;24(8):1006-1015. doi: 10.1111/ene.13337

15. Lee S, Mirsky DM, Beslow LA, Amlie-Lefond C, Danehy AR, Laura Lehman L, et al. Pathways for Neuroimaging of Neonatal Stroke. Pediatr Neurol. 2017;69:37-48. doi: 10.1016/j.pediatrneurol.2016.12.008

16. Sorg AL, von Kries R, Klemme M, Gerstl L, Weinberger $\mathrm{R}$, Beyerlein A, et al. Risk factors for perinatal arterial ischaemic stroke: a large case-control study. Dev Med Child Neurol. 2020;62(4):513-520. doi: 10.1111/dmcn.14347

17. Lee J, Croen LA, Backstrand KH, Yoshida CK, Henning LH, Lindan C, et al. Maternal and infant characteristics associated with perinatal arterial stroke in the infant. JAMA. 2005;293(6):723-729. doi: 10.1001/jama.293.6.723

18. Harteman JC, Groenendaal F, Kwee A, Welsing PMJ, Benders MJNL, de Vries LS. Risk factors for perinatal arterial ischaemic stroke in full-term infants: a case-control study. Arch Dis Child Fetal Neonatal Ed. 2012;97(6):F411-F416. doi: 10.1136/archdischild-2011-300973

19. Gupta R, Maraiyesa T, Conry B. Bilateral haemorrhagic basal ganglia infarction associated with early-onset group B streptococcus meningitis. BMJ Case Rep. 2018;2018:bcr2017223085. doi: 10.1136/bcr-2017-223085

20. Bang OY, Lee MJ, Ryoo S, Kim SJ, Kim JW. Patent Foramen Ovale and Stroke-Current Status. J Stroke. 2015;17(3):229237. doi:10.5853/jos.2015.17.3.229

21. Miranda B, Fonseca AC, Ferro JM. Patent foramen ovale and stroke. J Neurol. 2018;265(8):1943-1949. doi:10.1007/ s00415-018-8865-0

22. Fox CK, Glass HC, Sidney S, Smith SE, Fullerton HJ. Neonatal seizures triple the risk of a remote seizure after perinatal ischemic stroke. Neurology. 2016;86(23):2179 2186. doi: 10.1212/WNL.0000000000002739

23. Watson CG, Dehaes $M$, Gagoski BA, Grant PE, Rivkin MJ. Arterial Spin Labeling Perfusion Magnetic Resonance Imaging Performed in Acute Perinatal Stroke Reveals Hyperperfusion Associated With Ischemic Injury. Stroke. 2016;47(6):1514-1519. doi: 10.1161/ STROKEAHA.115.011936

24. Christy A, Murchison C, Wilson JL. Quick Brain Magnetic Resonance Imaging with Diffusion-Weighted Imaging as a First Imaging Modality in Pediatric Stroke. Pediatr Neurol. 2018;78:55-60. doi:10.1016/j.pediatrneurol.2017.09.020

25. Ernst M, Forkert ND, Brehmer L, Thomalla G, Siemonsen S, Fiehler J, et al. Prediction of infarction and reperfusion in stroke by flow- and volume-weighted collateral signal in MR angiography. Am J Neuroradiol. 2015;36(2):275-282. doi:10.3174/ajnr.A4145

26. Jin JH, Shin JE, Lee SM, Eun HS, Park MS, Park KI, et al. Abnormal neurodevelopmental outcomes are very likely in cases of bilateral neonatal arterial ischaemic stroke. Acta Paediatr Oslo Nor 1992. 2017;106(2):229-235. doi:10.1111/ apa.13655

27. Miller V. Neonatal cerebral infarction. Semin Pediatr Neurol. 2000;7(4):278-288. doi: 10.1053/spen.2000.20076

Author's Contribution: NY and XH conceived and designed the study. $\mathbf{C Y}$ and $\mathbf{L Z}$ collected the data and performed the analysis. NY and $\mathbf{X H}$ were involved in the writing of the manuscript and the integrity of the study. NY edited the manuscript.NY and $\mathbf{X H}$ are responsible for integrity of the study. All authors have read and approved the final manuscript 